\title{
Ocena najnowszych trendów w diagnozowaniu i leczeniu nowotworów złośliwych górnego odcinka układu pokarmowego na rok 2014 wg doniesień prezentowanych podczas konferencji ASTRO 56 w San Francisco
}

\section{Assessment of the latest trends in diagnosis and treatment of upper gastrointestinal malignancies for 2014 according to the reports presented at the ASTRO 56 conference in San Francisco}

\author{
Piotr Martenka ${ }^{1}$ \\ ${ }^{1}$ Wielkopolskie Centrum Onkologii
}

\section{Streszczenie}

Leczenie nowotworów złośliwych górnego odcinka układu pokarmowego, zarówno w USA, jak i w Europie, oparte jest o postępowanie wielodyscyplinarne. Podstawą terapii jest leczenie chirurgiczne, podczas gdy radioterapia i chemioterapia stosowane są głównie jako terapie uzupełniające. Wyniki dotychczasowych badań na temat skuteczności leczenia uzupełniającego są bądź sprzeczne, jak w przypadku stosowania radiochemioterapii w leczeniu raka trzustki, bądź znane są alternatywne schematy postępowania o podobnej skuteczności, których jednak nie porównano bezpośrednio, jak w przypadku leczenia uzupełniającego raka żołądka. O wyborze danego schematu leczenia uzupełniającego decydują lokalne preferencje. Ponieważ radioterapia w leczeniu uzupełniającym nowotworów złośliwych górnego odcinka układu pokarmowego ma więcej pozytywnych wyników badań klinicznych w USA - tam też częściej stosowana jest radiochemioterapia pooperacyjna w resekcyjnym raku żołądka czy trzustki, podczas gdy w Europie znacznie powszechniej stosowane są, odpowiednio okołooperacyjna chemioterapia w raku żołądka, czy pooperacyjna chemioterapia w raku trzustki, zgodnie z wynikami badań europejskich wykazujących większą skuteczność takiego postępowania.

\footnotetext{
Abstract

Adres do korespondencji

Lek. med. Piotr Martenka

Zastępca Ordynatora Oddziału Radioterapii Onkologicznej I

Wielkopolskie Centrum Onkologii,ul. Garbary 15, 61-866 Poznań, Polska

Telefon: +48618850867

e-mail: piotr.martenka@wco.pl
}

Treatment of upper gastrointestinal malignancies, both in the United States and in Europe, is based on multidisciplinary procedures. The basis of therapy is surgical treatment, while radiotherapy and chemotherapy 
are mainly used as adjuvant therapies. The results of previous studies on the efficacy of complementary therapies are either self-contradictory, as in the case of radio-chemotherapy for the treatment of pancreatic cancer, or alternative treatment regimens exist of similar efficacy that had not been directly compared in clinical trial, as in the case of adjuvant treatment for gastric cancer. Local preferences determine the choice of a treatment regimen. As radiotherapy in adjuvant treatment of upper gastrointestinal malignancies has more positive results of clinical trials performed in the United States, radio-chemotherapy for postoperative resectable gastric or pancreatic cancer is more commonly used there, while in Europe, perioperative chemotherapy in gastric cancer or postoperative chemotherapy in pancreatic cancer is more commonly used, according to the results of European studies showing such an approach to be more effective.

Słowa kluczowe: nowotwory złośliwe; przewód pokarmowy

Keywords: malignant neoplasms: digestive tract

\section{Wstęp}

Konferencja ASTRO odbywa się rokrocznie w Stanach Zjednoczonych. W roku 2014 odbyła się po raz pięćdziesiąty szósty, w San Francisco. Jest to największa na świecie konferencja, dotycząca radioterapii onkologicznej oraz jedna z największych i najważniejszych konferencji onkologicznych. Przez 5 dni od wczesnych godzin rannych do późnych popołudniowych odbywają się jednoczasowo sesje na kilkunastu salach wykładowych.

\section{Konferencja}

Dane kliniczne prezentowane są podczas konferencji w bardzo zróżnicowanych formach, takich jak:

- wykłady generalne (tzw. prezydenckie sesje) - prezentowane są dane o największym znaczeniu naukowo-klinicznym w opinii organizatorów konferencji. Typowo są to wyniki badań klinicznych 3 fazy, prezentacje nowych zaleceń klinicznych oraz wykłady dotyczące polityki zdrowotnej i onkologicznej w USA i na świecie,

- wykłady tematyczne - są to wykłady o charakterze edukacyjnym dydaktycznym ,podczas których prezentowane są aktualne zalecenia diagnostyczno-terapeutyczne. Wykłady te są jednocześnie elementem kształcenia podyplomowego amerykańskich specjalistów w dziedzinie onkologii,

- wykłady z konturowania - wymagają osobnej rejestracji. Przedstawiane są aktualne zalecenia dotyczące wyznaczania objętości terapeutycznych we współczesnej radioterapii trójwymiarowej opartej o planowanie tomograficzne. Wykłady są interaktywne i mają częściowo charakter ćwiczeń, podczas których uczestnicy mają możliwość samodzielnie wyznaczać objętości tarczowe oraz porównywać rezultaty z innymi uczestnikami. Wszelkie pytania lub wątpliwości są zgłaszane na bieżąco,

- wykłady dotyczące opisu trudnych przypadków klinicznych - o charakterze interaktywnym. Dzięki użyciu dostępnych dla każdego uczestnika małych tabletów wykładowcy mają możliwość na żywo zadawać pytania słuchaczom. Pytania mają formę testu jednokrotnego wyboru i dotyczą wyboru sposobu postępowania na danym etapie leczenia. Jest to więc na żywo wykonywane badanie typu „patterns of practice” - wyniki są w czasie rzeczywistym prezentowane jako element wykładu i dyskutowane przez prowadzących ekspertów. Wyniki odzwierciedlają aktualne przekonania i praktyki onkologów.

- $\quad$ sesje naukowe - są to wystąpienia ustne pogrupowane tematycznie. W czasie tych 90 minutowych sesji krótko , w czasie 7 -10 minut prezentowane są tematycznie wyniki projektów badawczych,

- sesje plakatowe elektroniczne - analogicznie do sesji naukowych jednak projekty przedstawiane są w telegraficznym skrócie ograniczającym się do przeczytania przez autora projektu treści plakatu w ciągu $5-7$ minut,

- wystawa plakatów - pogrupowane tematycznie. 


\section{Nowotwory górnego odcinka przewodu pokarmowego}

W przypadku nowotworów złośliwych górnego odcinka przewodu pokarmowego jedynie rak przełyku omawiany był podczas wykładów generalnych. Przedstawiono wyniki 2 badań randomizowanych 3 fazy $[1,2]$.

Odbyły się dwie sesje edukacyjne w zakresie nowotworów górnego odcinka przewodu pokarmowego. Podczas pierwszej omawiano w dwóch oddzielnych wykładach raka przełyku i żołądka. Podczas drugiej sesji na dwóch oddzielnych wykładach przedstawiono raka trzustki: resekcyjnego i granicznie resekcyjnego na pierwszym oraz zaawansowanego miejscowo i przerzutowego na drugim. Nie było wykładów edukacyjnych w zakresie pierwotnego raka wątroby, raka dróg żółciowych, czy raka dwunastnicy.

W zakresie nowotworów górnego układu pokarmowego odbyła się jedna sesja „trudne przypadki,, wspólna dla górnego i dolnego odcinka przewodu pokarmowego - przedstawiono 5 przypadków z zaplanowanych 6 z powodu dużej liczby pytań nie omówiono ostatniego przypadku. Dwa przypadki dotyczyły raka odbytnicy, jeden raka odbytu, jeden raka przełyku i jeden raka trzustki.

Odbyły się dwa kursy konturowania w zakresie nowotworów górnego układu pokarmowego. Podczas pierwszej przedstawiono przypadki raka przełyku - w odcinku proksymalnym, dystalnym oraz połączenia żołądkowo - przełykowego. Druga sesja obejmowała konturowanie raka trzustki przed- i pooperacyjnie.

Sesja naukowa dotycząca nowotworów górnego układu pokarmowego była jedna - dotyczyła wyłącznie raka przełyku.

\section{Rak przełyku}

Przedstawiono raporty z dwóch badań 3 fazy. Pierwsze dotyczyło chorych z rakiem przełyku w stadium choroby lub stanie ogólnym uniemożliwiającym leczenie radykalne [2]. W tym badaniu III fazy z losowym doborem próby, przeprowadzonym u pacjentów w Kanadzie, Wielkiej Brytanii i Nowej Zelandii, porównano dwie metody terapeutyczne: a) samodzielną radioterapię, b) radioterapię skojarzoną z chemioterapią. Dopuszczono dwa schematy radioterapii: 30Gy w 10 frakcjach oraz 35 Gy w 15 frakcjach. Jako chemioterapię stosowano cisplatynę i 5 - fluorouracyl jednoczasowo przez pierwsze 4 dni z radioterapią. W badaniu wzięło udział 210 pacjentów. Rozkład stratyfikacyjny w badanych grupach był równomierny. Nie zaobserwowano istotnych statystycznieróżnicwstopniu ustępowania dysfagiianiw medianieprzeżycia. Natomiaststwierdzono znamiennie wyższą toksyczność leczenia skojarzonego (nudności: $p=0,0019$, wymioty: $p=0,0072$ ). U 10 procent chorych obserwowano długotrwałe przeżycie całkowite, niezależnie od ramienia badawczego. Zatem samodzielna radioterapia pozostaje standardowym schematem postępowania paliatywnego u pacjentów z zaawansowanym lub przerzutowym rakiem przełyku. Ponadto u niewielkiej grupy chorych taki schemat leczenia skutkuje długotrwałym przeżyciem całkowitym.

Drugie dotyczyło chorych z rakiem przełyku leczonych radykalnie[1]. W tym badaniu, z losowym doborem próby, zaprojektowana dwa ramiona: radio-chemioterapię w schemacie 50,4Gy w 28 frakcjach oraz cotygodniowe podania cisplatyny w dawce $50 \mathrm{mg} / \mathrm{m}^{2}$ i paklitakselu w dawce $25 \mathrm{mg} / \mathrm{m}^{2}$ oraz w drugim ramieniu badania, identyczną radio-chemioterapię dodatkowo z cetuksymabem w schemacie $400 \mathrm{mg} / \mathrm{m}^{2}$ pierwszego dnia, następnie cotygodniowo $250 \mathrm{mg} / \mathrm{m}^{2}$. W badaniu nie stwierdzono żadnych istotnych statystycznie różnic w skuteczności terapeutycznej, w zakresie przeżycia całkowitego lub kontroli miejscowej. W przypadku toksyczności jedyna różnica dotyczyła, typowych po cetuksymabie, powikłań skórnych. Na podstawie tego badania oraz badania randomizowanego SCOPE można aktualnie z dużym prawdopodobieństwem stwierdzić, że cetuksymab nie znajdzie zastosowania w leczeniu raka przełyku w skojarzeniu z radykalną radio-chemioterapią [3].

Podczas sesji edukacyjnej stwierdzono, że w raku przełyku jedyną metodą leczenia, nie powinno być postępowanie chirurgiczne, z wyjątkiem stadium Tı̉ lub niższym. W przypadku zaawansowania wyższego niż T1b raki resekcyjne u chorych w dobrym stanie ogólnym powinny być leczone dwuetapowo: radiochemioterapią przedoperacyjną wg schematu badania CROSS z następową operacją [4]. W przypadkach nieresekcyjnych, miejscowo zaawansowanych, i/lub obciążeniu chorobami towarzyszącymi, należy rozważać samodzielną radio-chemioterapię, optymalnie, opartą na schematach chemioterapii mniej toksycznych niż cisplatyna i 5 - fluorouracyl. Radioterapia paliatywna nie powinna być kojarzona jednoczasowo z chemioterapią w miejscowo zaawansowanych przypadkach, u pacjentów w złym stanie ogólnym lub 
w stadium uogólnienia, zgodnie z wyżej omówionym badaniem grupy TROG [2].

Podczas sesji dotyczącej konturowania raka szyjnego i piersiowego odcinka przełyku stwierdzono, że nie istnieją jednolite, opublikowane zalecenia, z wyjątkiem guzów okolicy połączenia przełykowo-żołądkowego (typ Sievert I i II ), dla których opracowano konsensus opublikowany w 2009 roku [5]. W podejmowaniu decyzji o zakresie wybiórczego napromieniania poszczególnych grup węzłowych, należy kierować się ogólną zasadą maksymalnego ograniczania napromienianej objętości w przypadkach przedoperacyjnych oraz dostosowywać objęcie napromienianiem wybranych grup węzłowych do planowanego zakresu limfadenektomii operacyjnej.

Technika IMRT (ang. Intensity Modulated Radiation Therapy) w leczeniu raka przełyku wydaje się równie skuteczna i bardziej bezpieczna (mniej zgonów z powikłań kardiologicznych) niż technika 3DCRT (ang. Three - Dimensional Conformal Radiation Therapy) wg badania przeprowadzonego w Centrum MD Anderson w Teksasie [6]. Jednak w przypadku napromieniania długiego odcinka przełyku w celu ograniczenia ekspozycji dużej objętości płuc na niskie dawki radioterapii, wyrażone poprzez współczynnik objętościowy V5 <80\%, sugeruje się rozważenie stosowania techniki 3DCRT.

\section{Rak żołądka}

W trakcie sesji dotyczącej leczenia raka żołądka w stadium T2 lub wyższym lub (N+) bez przerzutów odległych przedstawiono różnice $\mathrm{w}$ postępowaniu terapeutycznym, dotyczące leczenia uzupełniającego leczenie chirurgiczne. W krajach azjatyckich stosuje się pooperacyjną chemioterapię preparatem S1 (doustny 5-FU) [7]. W Europie częściej stosowana jest chemioterapia okołooperacyjna w schemacie ECF, zgodnie z badaniem MAGIC lub chemio-radioterapia pooperacyjna. W USA preferowana jest opcja radiochemioterapii pooperacyjnej, a zalecana, lecz mało popularna, chemioterapia okołooperacyjna [8,9]. Aktualnie brak jest badań jednoznacznie wskazujących na optymalną taktykę leczenia loko-regionalnie zaawansowanego raka żołądka. W opinii wykładowcy, czwartą, niedocenianą możliwością jest radiochemioterapia przedoperacyjna [10]. Możliwe, że wyniki toczących się badań: CRITICS, TOPGEAR oraz ARTIST II ułatwią wybór optymalnego postępowania [11,12].

\section{Rak trzustki}

Rola uzupełniającej pooperacyjnej radio-chemioterapii raka trzustki pozostaje kontrowersyjna, głównie ze względu na sprzeczne wyniki kilku badań przeprowadzonych w latach 80-tych i 90-tych. Pierwsze wyniki RTOG 9704 wskazywały na jednoznacznie pozytywny wpływ radioterapii na współczynnik przeżycia całkowitego, jednak po dłuższej obserwacji utrzymał się jedynie trend poprawy mediany przeżycia: 20,5 vs. 17,1 miesięcy ( $\mathrm{p}=0.08)$ [13]. Techniki dostarczania promieniowania ewoluują, podobnie jak rozumienie właściwej objętości tarczowej. Technika i szczegóły anatomiczne planowania radioterapii mogą zwiększać współczynnik terapeutyczny, co wykazano analizując wyniki badania RTOG 9704. Chorzy, spełniający kryteria jakościowe $\mathrm{w}$ audycie (ang. per protocol-PP) mieli istotnie statystycznie lepsze wyniki leczenia w porównaniu do chorych, u których technika radioterapii nie była zgodna z przyjętym protokołem (ang. $<P P$ ) i wynosiły odpowiednio: mediana przeżycia 1,74 vs. 1,46 lat dla PP vs. < PP (p = 0,0077) [14]. Wyniki badań przeprowadzonych w ostatnich latach w USA wykazują, że leczenie uzupełniające radio-chemioterapią raka trzustki, zwłaszcza wysokiej jakości RT, jest korzystne u pacjentów, którzy mają szczególnie wysokie ryzyko loko-regionalnego nawrotu [15]. Jednak, jak wspomniano wyżej nie brakuje badań negatywnych, głównie europejskich, które niewątpliwie obfitują w liczne błędy metodologiczne, randomizacji, techniki radioterapii oraz prawidłowości założeń statystycznych [16,17]. Aktualnie prowadzone badanie amerykańskie RTOG o848 może doprecyzować rolę radio-chemioterapii w leczeniu uzupełniającym resekcyjnego raka trzustki [18].

W przypadku raka nieresekcyjnego lub granicznie resekcyjnego, kontrowersji co do optymalnego postępowania jest jeszcze więcej. Trudność w sprecyzowaniu zaleceń stanowi dodatkowo, poza wymienionymi wyżej przyczynami, problem wynikający z definiowania raka nieresekcyjnego i granicznie resekcyjnego. Według najnowszych publikacji trudno jest postawić jednoznaczny punkt odcięcia dla tych definicji i mówi się raczej o kontinuum resekcyjności przechodzącej w nieresekcyjność w zależności od kwalifikacji 
ośrodka, diagnostyki, doświadczenia chirurga, preferencji pacjenta etc. [19]. Badanie negatywne dla roli radio-chemioterapii prowadzono w ośrodkach europejskich - jest to badanie LAP o7, którego wyniki nie wykazały różnic w przeżyciu całkowitym między grupami chorych leczonych radioterapią i bez radioterapii w leczeniu miejscowo zaawansowanego nieresekcyjnego raka trzustki [20]. Nie znamy jednak dokładnych danych na temat jakości radioterapii, a dodatkowa analiza tego badania wskazuje, że chorzy bez progresji po wstępnej chemioterapii, którzy otrzymali radio-chemioterapię mieli dłuższy czas do lokalnego nawrotu choroby w porównaniu do tej grupy, która kontynuowała chemioterapię ( $34 \%$ vs $65 \%$ p <0,001 ). Niemniej kontrowersyjne jest badanie amerykańskie, którego wyniki sąpodstawą dla zaleceń krajowych w USA do stosowania w tym wskazaniu radio-chemioterapii. Jest to badanie randomizowane, na grupie zaledwie 74 chorych, opublikowane w 2011 roku, w którym wykazano istotny statystycznie zysk w medianie przeżycia całkowitego w grupie radio-chemioterapii: 9,2 miesięcy vs 11,1 miesięcy, ( p= 0,017 ) [21].

\section{Podsumowanie}

W aspekcie technicznym radioterapii stosowanie techniki IMRT w nowotworach układu pokarmowego jest w USA normą. Podczas spotkania ASTRO 56 przedstawiono nowe, istotne z punktu widzenia praktyki klinicznej, dane. W trakciegłównej sesji, dotyczącej wszystkich nowotworów, przedstawiono wyniki dwóch badań.Pierwszedotyczyłochorychzrakiemprzełykuwstadiumchorobylubstanieogólnymuniemożliwiającym leczenie radykalne. Konkluzja z tego badania jest taka, że samodzielna radioterapia pozostaje skutecznym $\mathrm{i}$ dobrze tolerowanym schematem postępowania paliatywnego $\mathrm{u}$ chorych $\mathrm{z}$ zaawansowanym $\mathrm{i} / \mathrm{lub}$ przerzutowym rakiem przełyku oraz, że w pewniej grupie chorych skutkuje długotrwałym przeżyciem. Kojarzenie jednoczasowo paliatywnej radioterapii z chemioterapią prowadzi jedynie do zwiększenia odsetka powikłań bez wpływu na efektywność terapii. Drugie badanie przestawione podczas tej sesji najważniejszych badań klinicznych dotyczyło pacjentów z rakiem przełyku leczonych radykalnie. Na podstawie tego badania można aktualnie z dużym prawdopodobieństwem stwierdzić, że cetuksymab nie znajdzie zastosowania w leczeniu raka przełyku, w skojarzeniu z radykalną radio-chemioterapią.

\section{Konflikt interesu / Conflict of interest}

Nie występuje / None

\section{Etyka / Ethics}

Treści przedstawione w artykule są zgodne z zasadami Deklaracji Helsińskiej, dyrektywami EU oraz ujednoliconymi wymaganiami dla czasopism biomedycznych.

\section{Piśmiennictwo/ References}

[1] Suntharalingam M, Winter K, Ilson D, et al. The Initial Report of Local Control on RTOG 0436: A Phase 3 Trial Evaluating the Addition of Cetuximab to Paclitaxel, Cisplatin, and Radiation for Patients With Esophageal Cancer Treated Without Surgery. Int. J. Radiat. Oncol. Biol. Phys., 90, S3.

[2] Penniment MG, Harvey JA, Wong R, Stephens S, Au H, O’Callaghan CJ, et al. Best Practice in Advanced Esophageal Cancer: A Report on Trans-Tasman Radiation Oncology Group TROG 03.01 and NCIC CTG ES.2 Multinational Phase 3 Study in Advanced Esophageal Cancer (OC) Comparing Quality of Life (QOL) and Palliation of Dysphagia in Patients Treated With Radiation Therapy (RT) or Chemoradiation Therapy (CRT). Int. J. Radiat. Oncol. Biol. Phys., 90, S3.

[3] Crosby T, Hurt CN, Falk S, Gollins S, Mukherjee S, Staffurth J, et al. Chemoradiotherapy with or without cetuximab in patients with oesophageal cancer (SCOPE1): a multicentre, phase 2/3 randomised trial. Lancet 2013;14:627-37

[4] van Hagen P, Hulshof MC, van Lanschot JJ, Steyerberg EW, van Berge Henegouwen MI, Wijnhoven BP. Preoperative Chemoradiotherapy for Esophageal or Junctional Cancer. N Engl J Med 2012; 366:20742084 May 31, 2012. 
[5] Matzinger O, Gerber E, Bernstein Z, Maingon P, Haustermans K, Bosset JF, et al. EORTC-ROG expert opinion: radiotherapy volume and treatment guidelines for neoadjuvant radiation of adenocarcinomas of the gastroesophageal junction and the stomach. Radiother Oncol. 2009 Aug;92(2):164-75.

[6] Lin SH, Wang L, Myles B, Thall PF, Hofstetter WL, Swisher SG, et al. Propensity score-based comparison of long-term outcomes with 3-dimensional conformal radiotherapy vs intensity-modulated radiotherapy for esophageal cancer. Int J Radiat Oncol Biol Phys. 2012; 84(5): 1078-1085.

[7] Sakuramoto S, Sasako M, Yamaguchi T, Kinoshita T, Fujii M, Nashimoto A, et al. Adjuvant Chemotherapy for Gastric Cancer with S-1, an Oral Fluoropyrimidine. N Engl J Med 2007; 357:1810-1820November 1, 2007.

[8] Cunningham D, Allum WH, Stenning SP, Thompson JN, Van de Velde CJ, Nicolson M, et al. Perioperative Chemotherapy versus Surgery Alone for Resectable Gastroesophageal Cancer. N Engl J Med 2006; 355:11-20July 6, 2006.

[9] Macdonald JS, Smalley SR, Benedetti J, Hundahl SA, Estes NC, Stemmermann GN, et al. Chemoradiotherapy after Surgery Compared with Surgery Alone for Adenocarcinoma of the Stomach or Gastroesophageal Junction. N Engl J Med 2001; 345:725-730September 6, 2001.

[10] Ajani JA, Winter K, Okawara GS, Donohue JH, Pisters PW, Crane CH, et al. Phase II trial of preoperative chemoradiation in patients with localized gastric adenocarcinoma (RTOG 9904): quality of combined modality therapy and pathologic response. J Clin Oncol. 2006 Aug 20;24(24):3953-8.

[11] Dikken JL, van Sandick JW, Maurits Swellengrebel HA, Lind PA, Putter H, Jansen EP, et al. Neoadjuvant chemotherapy followed by surgery and chemotherapy or by surgery and chemoradiotherapy for patients with resectable gastric cancer (CRITICS). BMC Cancer. 2011 Aug 2;11:329. doi: 10.1186/14712407-11-329.

[12] Leong T, Smithers BM, Michael M, Gebski V, Boussioutas A, Miller D, et al. TOPGEAR: a randomised phase III trial of perioperative ECF chemotherapy versus preoperative chemoradiation plus perioperative ECF chemotherapy for resectable gastric cancer (an international, intergroup trial of the AGITG/TROG/ EORTC/NCIC CTG). BMC Cancer. 2015;15:532.

[13] Regine WF, Winter KA, Abrams R, Safran H, Hoffman JP, Konski A, et al. Fluorouracil-based chemoradiation with either gemcitabine or fluorouracil chemotherapy after resection of pancreatic adenocarcinoma: 5-year analysis of the U.S. Intergroup/RTOG 9704 phase III trial. Ann Surg Oncol. 2011 May; 18(5):1319-26.

[14] Abrams RA, Winter KA, Regine WF, Safran H, Hoffman JP, Lustig R, et al. Failure to adhere to protocol specified radiation therapy guidelines was associated with decreased survival in RTOG 9704--a phase III trial of adjuvant chemotherapy and chemoradiotherapy for patients with resected adenocarcinoma of the pancreas. Int J Radiat Oncol Biol Phys. 2012 Feb 1; 82(2):809-16.

[15] Hsu CC, Herman JM, Corsini MM, Winter JM, Callister MD, Haddock MG, et al. Adjuvant chemoradiation for pancreatic adenocarcinoma: the Johns Hopkins Hospital-Mayo Clinic collaborative study.Ann Surg Oncol. 2010 Apr; 17(4):981-90.

[16] Van Laethem JL, Hammel P, Mornex F, Azria D, Van Tienhoven G, Vergauwe P, et al. Adjuvant gemcitabine alone versus gemcitabine-based chemoradiotherapy after curative resection for pancreatic cancer: a randomized EORTC-40013-22012/FFCD-9203/GERCOR phase II study. J Clin Oncol 2010;28:44506.

[17] Neoptolemos JP, Stocken DD, Friess H, Bassi C, Dunn JA, Hickey H, et al. A randomized trial of chemoradiotherapy and chemotherapy after resection of pancreatic cancer. N Engl J Med 2004;350:120010 .

[18] Chuong MD, Boggs DH, Patel KN, Regine WF. Adjuvant chemoradiation for pancreatic cancer: what does the evidence tell us? J Gastrointest Oncol. 2014 Jun; 5(3): 166-177.

[19] Ryan DP, Hong TS, Bardeesy N. Pancreatic Adenocarcinoma. N Engl J Med 2014; 371:1039-1049.

[20] Huguet F, Hammel P, Vernerey D, Goldstein D, van Laethem JL, Glimelius B, et al. Impact of chemoradiotherapy (CRT) on local control and time without treatment in patients with locally advanced pancreatic cancer (LAPC) included in the international phase III LAP o7 study. Journal of Clinical Oncology 32, no. 15_suppl (May 2014) 4001-4001

[21] Loehrer PJ Sr, Feng Y, Cardenes H, Wagner L, BrellJM, Cella D, et al. Gemcitabine alone versus gemcitabine plus radiotherapy in patients with locally advanced pancreatic cancer: an Eastern Cooperative Oncology Group trial. J Clin Oncol. 2011 Nov 1;29(31):4105-12. Epub 2011 Oct 3. 